Technical Report

\title{
Experimental Evaluation of Hyaluronidase Activity in Combination with Specific Drugs Applied in Clinical Techniques of Interventional Pain Management and Local Anaesthesia
}

Christoph Schulze, MD1,2, Thomas Bittorf, PD², Hermann Walzel, PD2, Günther Kundt, $\mathrm{PD}^{2}$, Rainer Bader, MD², Wolfram Mittelmeier, MD²

From: ${ }^{1}$ Military Hospital, Berlin, Germany; ${ }^{2}$ University of Rostock, Rostock, Germany.

Dr. Schulze is with the Department of Surgery, Military Hospital Berlin, Berlin; and the Institute of Medical Biochemistry and Molecular Biology, University of Rostock, Rostock, Germany.

Dr. Bittorf and Dr. Walzel are with the Institute of Medical Biochemistry and Molecular Biology, University of Rostock, Rostock, Germany.

Dr. Kundt is with the Department of Medical Informatics and Biometry, Rostock, Germany.

Dr. Bader and Dr. Mittelmeier are with the Department of Orthopedic Surgery, University of Rostock, Rostock, Germany.

Address correspondence: Thomas Bittorf Institute of Medical Biochemistry and Molecular Biology, University of Rostock Schillingallee 70, 18057 Rostock, Germany E-mail:

thomas.bittorf@med.uni-rostock.de

Disclaimer: There was no external funding in the preparation of this manuscript. Conflict of interest: None.

Manuscript received: 05/28/2008 Revised manuscript received: 07/30/2008 Accepted for publication: $10 / 13 / 2008$

Free full manuscript: www.painphysicianjournal.com
Background: Hyaluronidase is an enzyme additive used in local anaesthesia and interventional pain reducing procedures such as adhesiolysis of epidural scar tissue after spinal surgery. Only a limited number of studies describe the influence of drugs on hyaluronidase activity. Postulated effects and effectiveness of hyaluronidase are only based on clinical observations.

Objective: The aim of this study is to investigate the influence of the combined drugs on the activity of hyaluronidase under standardized conditions and to verify the effectiveness of the enzyme.

Design: An ELISA-based microtiter-technique is used to evaluate the activity of hyaluronidase in combination with local anaesthetics, corticosteroids, $\mathrm{NaCl} 10 \%$, and iodinated contrast media.

Methods: Microtiter plates were coated with biotinylated hyaluronate and incubated with hyaluronidase in combination with the above-mentioned drugs. The activity of hyaluronidase was determined by an avidin-peroxidase-based procedure using an ELISA reader. Incubations were carried out at room temperature as well as at $37^{\circ} \mathrm{C}$.

Results: The data show that drugs affect the activity of hyaluronidase in different ways. lodinated contrast media, $\mathrm{NaCl}(10 \%)$, and the absence of corticosteroids reduce hyaluronidase activity. In contrast, higher activities were detected at a lower $\mathrm{NaCl}$ concentration $(0.9 \%)$. We cannot attribute a significant influence to local anaesthetics.

Conclusions: Hyaluronidase is effective in all combinations with drugs. To get the maximum effect calculated use of accompanying drugs is necessary.

Key words: Hyaluronidase, enzymatic activity, adhesiolysis, local anaesthesia, pain management

Pain Physician 2008; 11:6:877-883 
H yaluronidases are used in different medical procedures. Enzymes belonging to this class mainly decompose hyaluronic acid, but they are also able to decompose chondroitin and chondroitinsulfate (1). The term hyaluronidase was introduced by Meyer et al (2). In vertebrates, tissue-specific hyaluronidases were identified which have been found to be different in characteristics like molecular weight, specificity, and $\mathrm{pH}$-optimum (3-6). The first therapeutical use of this enzyme was mentioned in 1928 as a so-called spreading factor which facilitates the uptake of subcutaneous applied vaccines and toxins (7). For therapeutical usage, most commonly, an enzyme derived from bovine testes is taken which implies hydrolytic and transglycosidic effects $(6,8,9)$. Via splitting of $\beta-1,4$-glycosidic bonding, hyaluronidases are able to degrade hyaluronic acid, chondroitin, chondroitin-4- and -6-sulfate as well as dermatan sulfate, which are the main components of the extracellular matrix (10).

Therapeutically this enzyme is used as a co-medication to local anaesthetics and drugs with pain reducing behavior. While the combination with local anaesthetics in local anaesthesia is long known and has been verified by clinical studies (11), the effect in epidural neuroplasty, according to Racz and Holubec where hyaluronidase is used in combination with local anaesthetics, corticosteroids, and $\mathrm{NaCl} 10 \%$, is only described in a few clinical studies (13). An in vitro laboratory investigation proving effectiveness or showing activity of hyaluronidase as already published for the use of opioids and $\alpha 2$-receptor agonists (14) is yet to be undertaken.

Epidural neuroplasty is considered to be an experimental procedure by the German Bundesärztekammer (15) due to the lack of randomized clinical studies. Addition of hyaluronidase is classified as not evidence based (16), although there are studies which observe successful treatments with low risks and complications $(13,17)$.

The procedures described above using hyaluronidase in combination with drugs are still in discussion concerning their effectiveness. Therefore, our study was designed to verify the effect of hyaluronidase in combination with drugs (i.e. Racz-technique) in vitro using standardized conditions.

\section{Methods}

COVALINK $^{\text {TM }}$-NH-Mikrotiter plates (NUNC, Wiesbaden, Germany) were used for all experiments.
HYLASETM "Dessau," prepared from bovine testes (Riemser Arzneimittel GmbH, Greifswald, Germany) was used as a source for hyaluronidase activity. All other chemicals were derived from Sigma (Taufkirchen, Germany).

\section{Preparation of Biotinylated Hyaluronate}

The following procedure is modified according to a published protocol (18). One hundred milligrams of human umbilical cord hyaluronate (Fa. Sigma) were dissolved in 0.1 M MES (Morpholine ethane sulfate), $\mathrm{pH} 5.0$ ) to a final concentration of $1 \mathrm{mg} / \mathrm{mL}$ and allowed to dissolve for at least $24 \mathrm{~h}$ at $4^{\circ} \mathrm{C}$ prior to the biotinylation. Biotin hydrazide (Fa. Pierce, Bonn) was dissolved in dimethyl sulfoxide as a stock solution of $100 \mathrm{mM}$ and added to hyaluronate solution to a final concentration of $1 \mathrm{mM}$. A stock solution of EDAC (1-ethyl-3 [3-dimethylaminopropyl] carbodiimide) was prepared as a $100 \mathrm{mM}$ stock solution in distilled water and added to the hyaluronate-biotin solution to a final concentration of $30 \mu \mathrm{M}$. This solution was left stirring over night at $4^{\circ} \mathrm{C}$. Unlinked biotin and EDAC were removed after the addition of $4 \mathrm{M}$ guanidinehydrochloride by dialysis against distilled water with 3 changes of 1,000 volumes of distilled water. The dialysed, biotinylated hyaluronate was aliquoted and stored at $-20^{\circ} \mathrm{C}$.

\section{Immobilization of Biotinylated Hyaluronate onto ELISA Plates}

For immobilization SULFO-NHS ${ }^{\mathrm{TM}}$ (N-Hydroxysulfosuccinimide)-biotin (Fa. Pierce) was diluted to $184 \mathrm{ng} /$ $\mathrm{mL}$ in distilled water with the biotinylated hyaluronate at a concentration of $200 \mathrm{ng} / \mathrm{mL}$ and pipetted into 96well COVALINK ${ }^{\mathrm{TM}}-\mathrm{NH}$ plates $(50 \mu \mathrm{l}$ per well). EDAC was diluted to a $123 \mathrm{ng} / \mathrm{mL}$ in distilled water and pipetted into the COVALINK ${ }^{\text {TM }}$ plates with the hyaluronate solution resulting in a final concentration of $10 \mu \mathrm{g} /$ well hyaluronate and $6.15 \mu \mathrm{g} /$ well EDAC. The plates were incubated for 2 hours at room temperature or overnight at $4^{\circ} \mathrm{C}$, with comparable results. After the covalent immobilization of biotinylated hyaluronate on the microtiter plates, the coupling solution was removed by shaking and the plates were washed 3 times in buffer A (PBS, Phosphate Buffered Saline [GIBCO, Karlsruhe] containing $2 \mathrm{M} \mathrm{NaCl}$ and $50 \mathrm{mM} \mathrm{MgSO}_{4}$ ).

\section{Determination of Hyaluronidase Activity}

$100 \mu \mathrm{l}$ of each reaction mixture was pipetted into coated wells of microtiter plates and incubated for a 
defined period. All samples were done in triplicate. The reaction was stopped by adding $200 \mu$ l of a $6 \mathrm{M}$ guanidine hydrochloride solution. The procedure was continued with 3 washes with buffer B (PBS, Tween20 $0.05 \%, 2 \mathrm{M} \mathrm{NaCl}, 50 \mathrm{mM} \mathrm{MgSO}_{4}$ ) and followed by the incubation with avidin-peroxidase. Avidin-peroxidase was diluted 1:15,000 in PBS containing Tween20 (0.1\%)/BSA (5\%, Bovine Serum Albumin), transferred to the microtiter plates $(100 \mu \mathrm{l} /$ well $)$ and incubated at room temperature for $30 \mathrm{~min}$. Incubation was followed by 6 washes with PBS (Tween20 0.1\%, BSA 5\%). Afterwards a solution of $100 \mu$ OPD (o-phenylenediamine) was added. This solution was prepared by dissolving a $10 \mathrm{mg}$ tablet in $10 \mathrm{~mL} 0.1 \mathrm{M}$ citrate-phosphate buffer (pH 5.3) and $7.5 \mu \mathrm{H}_{2} \mathrm{O}_{2}$ (Fa. Merck, Haar). Five minutes later the reaction was terminated by addition of $50 \mathrm{\mu l} 5 \mathrm{M} \mathrm{H}_{2} \mathrm{SO}_{4}$ (Fa. Merck, Haar) and the extinction was measured by means of an ELISA reader (AR 2001, Anthos Labtec Instruments, Salzburg) using a $492 \mathrm{~nm}$ filter (3 independent readings).

\section{Statistical Methods}

For all continuous variables measures of descriptive statistics (mean, standard error [SE]) were computed. Trends were determined by using linear regression analysis (Fig. 1 and 2). Testing on normality was done by means of the Kolmogorov-Smirnov test (Fig. 3). The

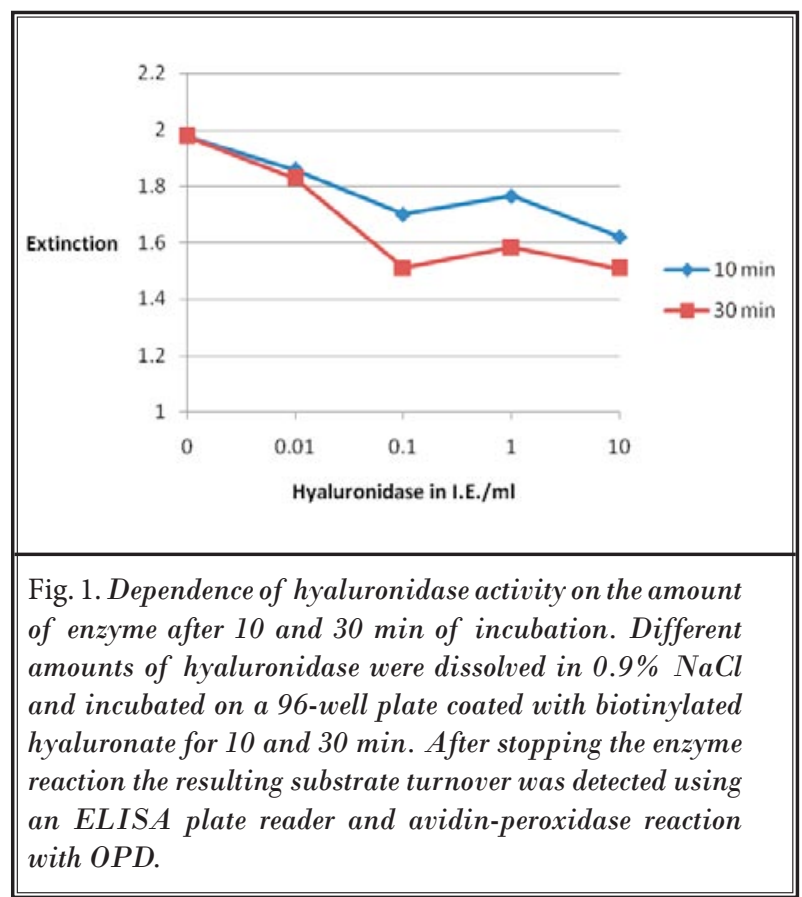

comparison of 5 drug combinations between different temperatures was realized using the t-test for dependent samples. All $p$ values resulted from 2 -sided statistical tests and $p \leq 0.05$ was considered to be significant. Data analysis was performed using the SPSS statistical package 15.0 (SPSS Inc. Chicago, Illinois).

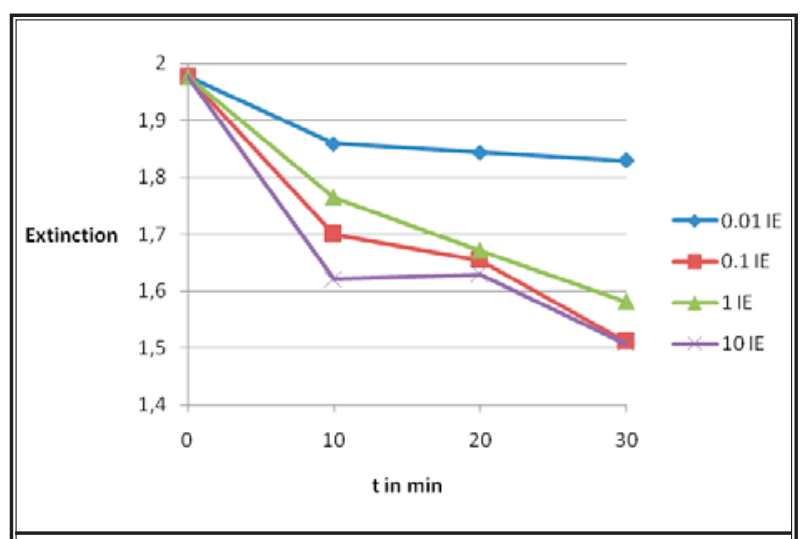

Fig. 2. Time course of hyaluronidase activity using different amounts of enzyme. Different amounts of hyaluronidase were dissolved in $0.9 \% \mathrm{NaCl}$ and incubated on a 96-well plate coated with biotinylated hyaluronate for different times. Enzyme activity was determined as described above.

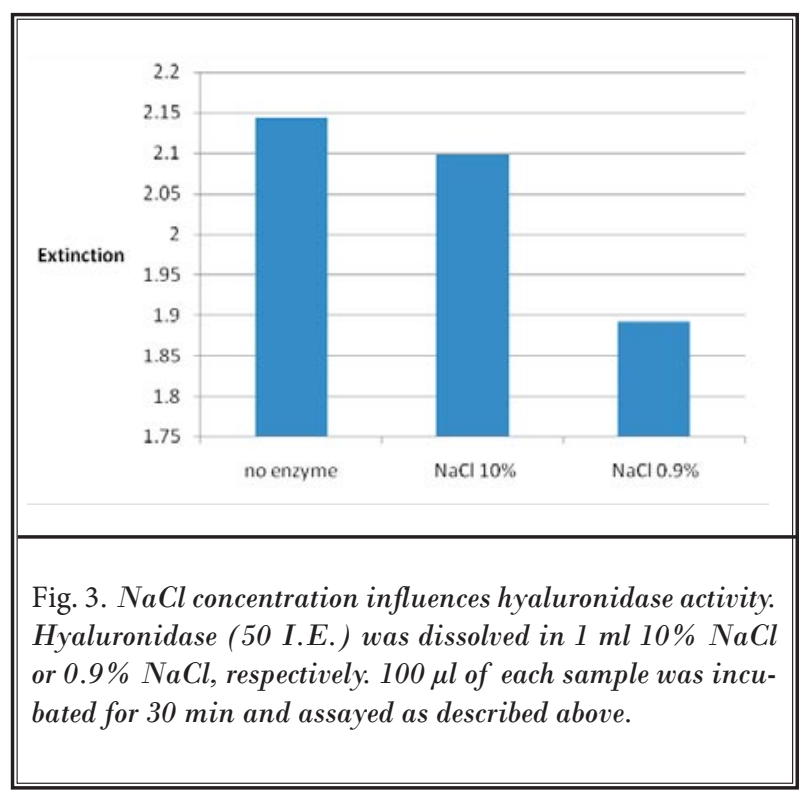




\section{Results}

\section{Dose-Dependency of Hyaluronidase Activity}

Initially we wanted to demonstrate a dose dependent increase of hyaluronidase activity by using enzyme concentrations between 0.01 I.E. and 10 I.E/well, which were assayed after different times of incubation. To ensure optimal reaction conditions hyaluronidase was dissolved in a special buffer (0.1 M formate, $\mathrm{pH} 4,5$, $0.15 \mathrm{M} \mathrm{NaCl}, 1 \%$ Triton $\mathrm{X}-100,5 \mathrm{mM}$ saccharolactone). The course of extinction after 10 and 30 minutes of incubation is shown in Fig. 1. Increasing amounts of enzyme result in a higher substrate turnover (sinking values of extinction) pointing to the presence of higher enzyme activities. The linear regression equation displayed a slope of -0.022 for the short incubation (10 minutes,) which means a decrease of extinction of 0.22 for a 10 -fold higher concentration of enzyme. 30 minutes of incubation led to a decrease of extinction of about 0.24 . This result also proves that an increasing time of incubation leads to an increased turnover of substrate (Figs. 1 and 2). These data demonstrate that hyaluronidase activity is dependent on both the time of incubation and the amount of enzyme (Fig. 2). The 4 different amounts of enzyme tested produced different slopes in the regression equations of -0.005

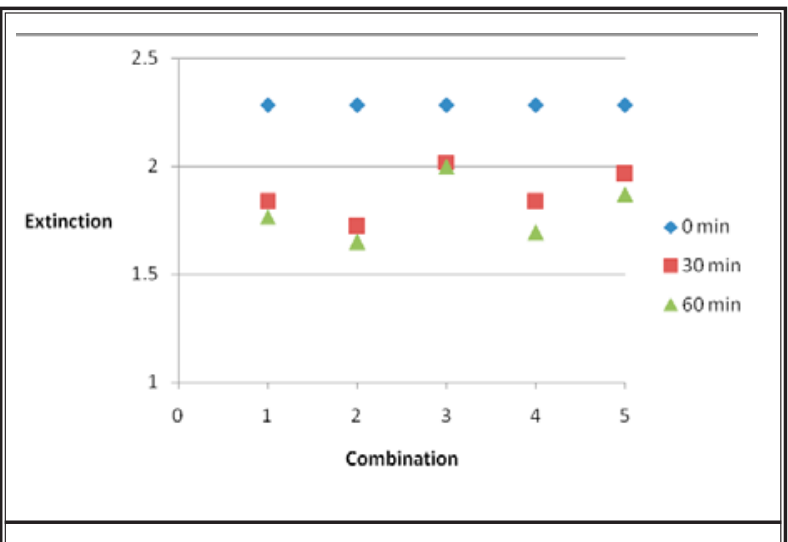

Fig. 4. Hyaluronidase dependent substrate turnover in combination with specific drugs at room temperature. Drug combinations are listed in Table 1. Specific drugs were combined with $50 \mathrm{I}$.E./ml hyaluronidase. Except combination 3, where $0.9 \% \mathrm{NaCl}$ was used, hyaluronidase was dissolved in 10\% NaCl and combined with SOLUTRUST TM 300, NAROPIN TM, and Triamcinolon. 100 pl of each sample was incubated and assayed as described above.
(0.01 I.E.), -0.014 (0.1 I.E.), -0.013 (1 I.E.), and -0.014 (10 I.E.). That means an incubation longer than $10 \mathrm{~min}-$ utes leads to an average decrease of extinction of 0.05 (0.01 I.E.), 0.14 (0.1 I.E.), 0.13 (1 I.E.), and 0.14 (10 I.E.).

\section{Influence of specific drugs on hyaluronidase activity}

Next, we added the following drugs, NAROPIN ${ }^{\mathrm{TM}}$ (Ropivacain hydrochloride $2 \mathrm{mg} / \mathrm{ml}$, Astra Zeneca, Wedel) as local anaesthetic, Triamcinolone acetonid (VOLON $^{\mathrm{TM}}$ A 40, Bristol-Myers Squibb, München) as a corticosteroid, $0.9 \%$ and $10 \% \mathrm{NaCl}$ (Braun AG, Melsungen) as well as the iodinated contrast media SOLUTRUST 300 ${ }^{\text {TM }}$ (Byk Gulden, Konstanz), to a therapeutically used dose of 50 I.E./mL hyaluronidase. Table 1 summarizes the investigated drug combinations as well as the amounts used.

In all combinations a strong decrease of substrate levels is shown after a period of 30 minutes (Fig. 4). The extinction decreased on average from 2.28 to 1.87. Therefore, it can be concluded that there is a high hyaluronidase activity present in the beginning. While the decrease continued in combination 4 from 30 to 60 minutes (1.84 to 1.69), the turnover in combination $1,2,3$, and 5 nearly stagnated (average 0.06 ). The highest initial activity was observed with a low $(0.9 \%) \mathrm{NaCl}$ concentration. Contrast media seems to inhibit enzyme activity (combination 4, Fig. 4). A possible reason for this may be that a combination lacking SOLUTRUST $300^{\mathrm{TM}}$ displays a higher stability of hyaluronidase activity (higher decrease of enzyme activity from 30 to 60 minutes in combinations $(1,2,3$, and 5 , Fig. 4). The presence of corticosteroids has a slightly positive effect on the hyaluronidase activity. In the absence of corticosteroids the activity of hyaluronidase decreased (combination 3). NAROPIN ${ }^{\mathrm{TM}}$ was found to have no effects on hyaluronidase (combination 5 ). To define the influence of the $\mathrm{NaCl}$-concentration we performed separate experiments.

\section{Influence of $\mathrm{NaCl}$-concentration on Hyaluroni- dase Activity}

50 I.E. hyaluronidase were dissolved in either $1 \mathrm{~mL}$ $\mathrm{NaCl} 10 \%$ or $0.9 \% .100 \mu \mathrm{l}$ of each solution was added into a prepared well coated with substrate. The hyaluronidase activity was measured after 30 minutes of incubation. The results clearly show that low concentrations of $\mathrm{NaCl} 0.9 \%$ promote higher levels of activity (Fig. 3). The hypothesis of uniform distribution was not rejected for the extinctions presented $(p=0.689)$. 
Table 1. Drug combinations with hyaluronidase.

\begin{tabular}{|l|c|c|c|c|c|}
\hline Combination & 1 & 2 & 3 & 4 & 5 \\
\hline $\begin{array}{l}\text { SOLUTRUST } \\
300^{\mathrm{TM}}\end{array}$ & $317 \mu \mathrm{l}$ & $317 \mu \mathrm{l}$ & $317 \mu \mathrm{l}$ & - & $317 \mu \mathrm{l}$ \\
\hline NAROPIN $^{\mathrm{TM}}$ & $317 \mu \mathrm{l}$ & $317 \mu \mathrm{l}$ & $317 \mu \mathrm{l}$ & $317 \mu \mathrm{l}$ & - \\
\hline $\mathrm{NaCl} 10 \%$ & $333 \mu \mathrm{l}$ & - & $333 \mu \mathrm{l}$ & $333 \mu \mathrm{l}$ & $333 \mu \mathrm{l}$ \\
\hline $\begin{array}{l}40 \mathrm{mg} / \mathrm{mL} \\
\text { Triamcinolon }\end{array}$ & $33 \mu \mathrm{l}$ & $33 \mu \mathrm{l}$ & - & $33 \mu \mathrm{l}$ & $33 \mu \mathrm{l}$ \\
\hline $0.9 \% \mathrm{NaCl}$ & - & $333 \mu \mathrm{l}$ & $33 \mu \mathrm{l}$ & $317 \mu \mathrm{l}$ & $317 \mu \mathrm{l}$ \\
\hline $\begin{array}{l}\text { HYLASE } \\
\text { Dessau }\end{array}$ & 50 I.E. & 50 I.E. & 50 I.E. & 50 I.E. & 50 I.E. \\
\hline Total & $1 \mathrm{~mL}$ & $1 \mathrm{~mL}$ & $1 \mathrm{~mL}$ & $1 \mathrm{~mL}$ & $1 \mathrm{~mL}$ \\
\hline
\end{tabular}

\section{Influence of Temperature on Hyaluronidase} Activity in Combination with Specific Drugs

To analyse the role of incubation temperature we incubated equal samples at $37^{\circ} \mathrm{C}$ as well as at room temperature. The data show that the turnover is significantly increased at $37^{\circ} \mathrm{C}$ compared to the samples treated at room temperature (Fig. 5). The extinction decreased on average from 1.87 (room temperature) to $1.41\left(37^{\circ} \mathrm{C}\right)(p=0.013)$. Decrease of extinction at $37^{\circ} \mathrm{C}$ compared to basic levels is 2 -fold higher as at room temperature. Obviously, hyaluronidase activity depends on temperature in all drug combinations tested. Conspicuously the absence of corticosteroids (combination 3 ) leads to a reduced turnover of substrate. The almost mentioned influence of the $\mathrm{NaCl}$ concentration on enzyme activity could be observed again.

\section{Discussion}

The aim of our investigation was to determine the influence of specific drugs used in interventional pain management and local anaesthesia on hyaluronidase activity. To our knowledge there has been no experimental study proving the effectiveness of hyaluronidase under conditions used in clinical applications. The few clinical studies published so far suffer from the lack of direct evidence of hyaluronidase activity as well as from the influence of patient-related individual factors, i.e. the irrigation effects produced when substances are placed in the epidural space.

Our results suggest that there is no negative effect on hyaluronidase activity when local anaesthetics

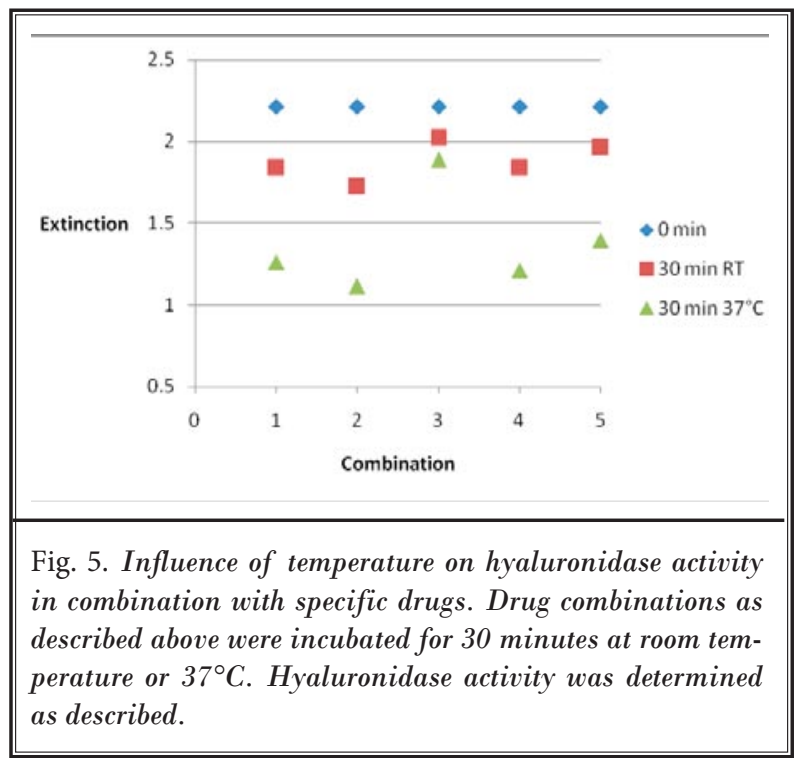

are added. It can be concluded that this combination is effective in local anaesthesia, the clinical profit has been shown already (11). Hyaluronidase in combination with contrast media is applied in the procedure of epidural neuroplasty (12) to verify the correct localization of the catheter. Our data demonstrate that the contrast media reduces the activity of hyaluronidase. To ensure an optimal hyaluronidase activity, contrast media should therefore be avoided if possible. Otherwise, it should be taken into account that suboptimal enzyme activities reduce the effects in vivo.

Our results demonstrate the temperature dependent effectiveness of hyaluronidase. This is in agreement to the results of Schülke et al (19) which demonstrate increasing hyaluronidase activities following a rise of temperature to $37^{\circ} \mathrm{C}$. For bovine testes hyaluronidase the optimal temperature was shown to be $39^{\circ} \mathrm{C}(19)$.

$\mathrm{pH}$ is a further determinant in the activity of hyaluronidase. In our first line experiments (Fig. 1 and 2) $\mathrm{pH}$ was about 4.5 , which is known to be the optimal pH for this enzyme (20). In our second line experiments (Figs. 3-5) pH was about 6.9 \pm 0.1 . Although the activity of hyaluronidase is lower, hyaluronidase has been shown to be active at neutral $\mathrm{pH}$ values $(21,22)$.

For hyaluronidase/drug combinations lacking cortisone, we noticed a decrease in hyaluronidase activity suggesting a direct positive effect of corticosteroids on hyaluronidase activity. Interestingly, an increased 
hyaluronidase activity was observed in sperm of rams after intramuscular application of dexamethasone which seems to be due to an increased liberation from lysosomes (23). It should be stated, however, that our experiments are restricted to the chemical interaction of the corticosteroid with the enzyme and not the effects induced in cells. Additionally, the anti-inflammatory effect of corticosteroids complements the effects of hyaluronidase in the procedure of epidural neuroplasty.

Our results prove that the concentration of $\mathrm{NaCl}$ is of importance for the activity of hyaluronidase. A physiological concentration leads to a higher level of enzyme activity than a hypertonic $\mathrm{NaCl}$ solution. Yang and Srivastav (24) postulated $\mathrm{NaCl}$ as a stabilizer for hyaluronidase. In a clinical study on percutaneous epidural adhesiolysis, however, no advantage was seen for the use of $0.9 \% \mathrm{NaCl}$ versus $10 \% \mathrm{NaCl}$ with or without hyaluronidase (25). It should be mentioned that $\mathrm{NaCl} 10 \%$ exerts an antioedematous effect (12).

\section{Conclusion}

Taken together it can be concluded that hyaluronidase is effective in all combinations with drugs. Therefore, the data provide experimental evidence for the postulated effects of different procedures in interventional pain management and local anaesthesia. It must, however, be taken into consideration that hyaluronidase is influenced by the presence of corticosteroids, contrast media, and the concentration of $\mathrm{NaCl}$ in different ways. Contrast media should only be used if it is absolutely necessary. Local anaesthetics have no significant influence on hyaluronidase activity and can therefore be combined without negative effects whereas corticosteroids exerts a positive effect. The effects of the drug combinations analysed in this study have not been investigated in clinical studies so far. Suggestions derived from our findings should be therefore verified in clinical studies.

\section{References}

1. Stern R, Jedrzejas MJ. Hyaluronidases: Their genomics, structures, and mechanisms of action. Chem Rev 2006; 106: 818-839.

2. Meyer K, Hobby G, Chaffee E, Dawson $\mathrm{MH}$. The relationship between spreading factor and hyaluronidase. Proc Soc Exptl Biol Med 1940; 44:294.

3. Csoka TB, Frost GI, Stern R. Hyaluronidases in tissue invasion. Invasion Metastasis 1997; 17:297-311.

4. Frost GI, Csoka TB, Stern R. The hyaluronidases: A chemical, biological and clinical overview. Trends Glycosci Glycotechnol 1996; 8:419-434.

5. Kreil G. Hyaluronidases - A group of neglected enzymes. Protein Sci 1995; 4:1666-1669.

6. Meyer K. Hyaluronidases. The Enzymes. Boyer PD Vol V 3rd Ed; Academic Press, New York, London, 1971; 307-320.

7. Duran-Reynals F. Exaltation de l'activite du virus vaccinal par les extraits de certain organes. CR Seances Soc Biol Fil 1928; 99:6-7.

8. Baumgartner G, Moritz A. Hyaluronidase: Anwendung in der Onkologie. Springer Wien, Berlin, Heidelberg, New York, 1988.
9. Menzel EJ, Farr C. Hyaluronidase and its substrate hyaluronan: Biochemistry, biological activities and therapeutic uses. Cancer Lett 1998; 131:3-11.

10. Takagaki K, Nakamura T, Izumi J, Saitoh H, Endo M, Kojima K, Kato I, Majima $M$. Characterisation of hydrolysis and transglycosylation by testicular hyaluronidase using ionspray mass spectrometry. Biochemistry 1994; 33:65036507.

11. Moore DC. The use of hyaluronidase in local and nerve block analgesia other than spinal block. 1520 cases. Anaesthesiology 1951; 12:611-626.

12. Racz GB, Holubec JT. Lysis of adhesions in the epidural space. In: Raj P (ed.) Techniques of Neurolysis. Kluwer Academic Publishers, Boston, 1989; 57-72.

13. Gerdesmeyer L, Rechl H, Wagenpfeil S Ulmer M, Lampe R, Wagner K. Minimally invasive percutaneous epidural neurolysis in chronic radiculopathy. A prospective controlled pilot study to prove effectiveness. Orthopade 2003; 32: 869-876.

14. Guneli E, Yavasoglu NUK, Apaydin S, Uyar Mel, Uyar Meh. Analysis of the antinociceptive effect of systemic administration of tramadol and dexmedeto- midine combination on rat models of acute and neuropathic pain. Pharmacol Biochem Behav 200; 88:9-17. Epub 2007 Jun 28.

15. Klakow-Franck R, Rheinberger P. Mitteilungen: Stellenwert der minimalinvasiven Wirbelsäulenkathetertechnik nach Racz. Dtsch Ärztebl 2003; 100: A1022-1023.

16. Boswell MV, Trescot AM, Datta S, Schultz DM, Hansen HC, Abdi S, Sehgal N, Shah RH, Singh V, Benyamin RM, Patel VB, Buenaventura RM, Colson JD, Cordner HJ, Epter RS, Jasper JF, Dunbar EE, Atluri SL, Bowman RC, Deer DR, Swicegood JR, Staats PS, Smith HS, Burton AW, Kloth DS, Giordano J, Manchikanti L. Interventional techniques: Evidencebased practice guidelines in the management of chronic spinal pain. Pain Physician 2007; 10:7-111.

17. Gerdesmeyer L, Lampe R, Veihelmann A, Burgkart R, Göbel M, Gollwitzer H, Wagner K. Chronic radiculopathy. Use of minimally invasive percutaneous epidural neurolysis according to Racz. Schmerz 2005; 19:285-295.

18. Frost GI, Stern R. A microtiter-based assay for hyaluronidase activity not requiring specialized reagents. Analytical 
Biochemistry 1997; 251:263-269.

19. Schülke B, Jacobi K, Schwan K, Schröder A, Tegeler G, Hahn S. Hyaluronidase release in bull sperm-influence of media and temperature. Arch Exp Veterinarmed 1990; 44:135-142.

20. DeSalequi M, Plonska H, Pigman W. A comparison of serum and testicular hyaluronidase. Arch Biochem Biophys 1967; 121:548.

21. Csoka AB, Frost GI, Heng HH, Scherer SW, Mohapatra G, Stern R, Csoka TB.
The hyaluronidase gene HYAL1 maps to chromosome 3p21.2-p21.3 in human and $9 \mathrm{~F}_{1}-\mathrm{F}_{2}$ in mouse, a conserved candidate tumor suppressor locus. Genomics 1998; 48:63-70.

22. Tung JS, Mark GE, Hollis GF. A microplate assay for hyaluronidase and hyaluronidase inhibitors. Anal Biochem 1994; 223:149-152

23. Gur S, Bozkurt T, Türk G. Short term effects of dexamethasone on hyaluronidase activity and sperm characteristics in rams. Anim Reprod Sci 2005. 90:255263.

24. Yang C, Srivastav P. Purification and properties of hyaluronidase from bull sperm. J Biol Chem 1975; 10:250:7983.

25. Heavner JE, Racz GB, Raj P. Percutaneous epidural neuroplasty: Prospective evaluation of $0.9 \% \mathrm{NaCl}$ versus $10 \%$ $\mathrm{NaCl}$ with or without hyaluronidase. Reg Anesth Pain Med 1999; 24:202207. 
